\title{
Cultivation of the bacterium Azotobacter chroococcum for preparation of biofertilizers
}

\author{
Oros Damir, Pavlečić Mladen, Šantek Božidar* and Novak Srđan \\ Department of Biochemical Engineering, Faculty of Food Technology and Biotechnology, University of Zagreb, \\ Pierottijeva 6/IV, Zagreb HR-10000, Croatia. \\ Accepted 10 March, 2011
}

\begin{abstract}
The biomass of the bacterium Azotobacter chroococcum can be used as a biofertilizer due to its ability to fix nitrogen from the atmosphere. In order to optimize the production of bacterial biomass for this purpose, a cultivation of $A$. chroococcum was done by using different media and cultivation techniques (batch, fed batch and repeated batch). Chemically defined and complex media with $20 \mathrm{~g} / \mathrm{l}$ of sugar were selected as the most appropriate media for batch cultivation in stirred tank bioreactor. In order to obtain higher fed batch and repeated batch techniques were examined. During these cultivations, increase of bioprocess efficiency parameters (yield coefficient and productivity) were observed compared with the batch cultivation. On the basis of the obtained results, repeated batch technique appeared to be the most suitable for the bacterial biomass production at industrial scale.
\end{abstract}

Key words: Azotobacter chroococcum, chemically defined and complex media, different cultivation techniques, biofertilizers.

\section{INTRODUCTION}

Biofertilizers are substances that contain living microorganisms, when they are applied to seed, plant surfaces or soil; these microorganisms colonize the rhizosphere or the interior of the plant and promote growth by increasing the supply or availability of primary nutrients to the host plant (Revillas et al., 2000; Vessey, 2003). In agriculture, the use of artificial fertilizers still ensures better yields, but soils and the environment become more polluted and depleted of important nutrients. Biofertilizers can contain symbiotic or non-symbiotic microorganisms that stimulate the growth of plants. Cultivation of plants with biofertilizers can result in higher resistance of plants to diseases and the production of phytohormones and water soluble vitamins. Furthermore, microorganisms can increase plant growth rates (Kumar et al., 2001; Behl et al., 2003; Kumar et al., 2008).

One of the most interesting non-symbiotic bacteria that have great potential for use in production of biofertilizers is Azotobacter chroococcum, due to its ability to fix atmospheric nitrogen $\left(\mathrm{N}_{2}\right)$ into ammonia, in a reaction

${ }^{*}$ Corresponding author. E-mail: bsantek@pbf.hr. Tel: 385-14605-290. Fax: 385-1-4836-424. catalyzed by the nitrogenase enzyme complex. This complex is very sensitive to oxygen concentration and it has one of the highest reaction rates in $A$. chroococcum metabolism (Yates et al., 1997; Sabra et al., 2000; Bakulin et al., 2007). The growth of $A$. chroococcum is affected by temperature that has to be in the range of 28 to $32^{\circ} \mathrm{C}$, while the $\mathrm{pH}$ should be kept between 7.0 and 7.5. Dissolved oxygen concentration and medium composition (especially salt concentration) have also considerable impact on the bacterial growth (Lees and Postgate, 1973; Hine and Lees, 1976; Pozo et al., 2002; Kisten et al., 2006). Some nitrogen containing salts, promote bacterial growth by reducing the duration of the lag phase (Juarez et al., 2005). In the presence of high carbohydrate concentration in broth (> $30 \mathrm{~g} / \mathrm{l})$, $A$. chroococcum accumulates significant quantities of intracellular energy storage material (poly- $\beta$-hydroxybutyrate; PHB). PHB synthesis in $A$. chroococcum is also stimulated by cultivation in oxygen-limited conditions ( $\mathrm{Pal}$ et al., 1997; Savenkova et al., 1999; Kim, 2000; Quagliano et al., 2001). During cultivation of $A$. chroococcum at higher oxygen concentration, an alginate capsule, with a relatively high guluronic acid content is formed on the cell surface. A similar effect was also observed during cultivation of Azotobacter vinelandii 
(Segura et al., 2003a; Gimmestad et al., 2006). This alginate capsule can be released into the medium and it makes an effective barrier that restricts oxygen transfer into the cell and consequently, more intensive aeration has to be used to ensure sufficient oxygen supply during cultivation (Sabra et al., 2001). It is known that, an increase of the L-guluronic acid fraction in the alginate leads to the formation of dense gels as a consequence of interaction between alginate chains that produces the increase of broth viscosity (Sabra et al., 2000). A. chroococcum can also form an outer layer that is called a cyst and it protects cells from undesirable environmental conditions. Bacterial polymers related to the formation of cysts are PHB, alginate, alkylresorcinols, 5-n-heneicosylresorcinol, 5-n-tricosylresorcinol and their galactoside derivatives. Alkylresorcinols are lipids that replace the membrane phospholipids during encystment and are also components of the outer layer of the cyst (Pena et al., 2002, Segura et al., 2003a; Segura et al., 2003b; Funa et al., 2006).

Cultivation of $A$. chrooccocum is characterised by relatively low dry biomass concentrations (MartinezToledo et al., 1995; Quagliano et al., 2001; Pozo et al., 2002; Kisten et al., 2006) and therefore, it is necessary to examine different cultivation techniques (batch, fed batch, semi-continuous or continuous) in order to obtain higher cell yield. In bioprocess industry, batch and fed batch techniques are still most often used. However, semicontinuous and continuous techniques have also been reported but in considerably lower extent compared with the first two techniques. In industry, semi-continuous technique is mostly used for the production of organic acids (acetic acid). Continuous technique is still the most challenging one, especially for conduction of bioprocesses in large scale. It is mostly used for microbial biomass production (yeast and bacteria) and waste water treatment (Moser, 1988). Until now, batch and fed batch cultivation techniques were mostly used for the study of the growth of $A$. chroococcum in different conditions (Savenkova et al., 1999; Quagliano et al., 2001; Kisten et al., 2006). Continuous cultivation of $A$. chroococum was performed in order to study the bacterial physiology in different experimental conditions (Lees and Postgate, 1973; Hine and Lees, 1976).

The aim of this work was to define the medium content as well as to select the most appropriate cultivation technique for large scale cultivation of bacterium $A$. chroococcum.

\section{MATERIALS AND METHODS}

\section{Microorganism, maintenance and growth conditions}

A. chroococcum (DSM 2286) was cultivated at $30^{\circ} \mathrm{C}$ on different media. Cultures were kept at $4^{\circ} \mathrm{C}$ on a chemically defined medium that consisted of $(\mathrm{g} / \mathrm{l}): \mathrm{MgSO}_{4} \cdot 7 \mathrm{H}_{2} \mathrm{O}, 0.10 ; \mathrm{Na}_{2} \mathrm{MoO}_{4} \cdot 2 \mathrm{H}_{2} \mathrm{O}, 0.03$; $\mathrm{CaCl}_{2} \cdot 2 \mathrm{H}_{2} \mathrm{O}, 0.45 ; \mathrm{KH}_{2} \mathrm{PO}_{4}, 0.80 ; \mathrm{FeSO}_{4} \cdot 7 \mathrm{H}_{2} \mathrm{O}, 0.05$; glucose 10 and agar $20(\mathrm{pH}=7.0)$. This medium was also used for colony forming units (CFU) determination.

\section{Cultivation of $\boldsymbol{A}$. chroococcum on rotary shaker}

A. chroococcum was cultivated in $500 \mathrm{ml}$ Erlenmeyer flasks with $200 \mathrm{ml}$ of broth (180 ml of medium and $20 \mathrm{ml}$ of inoculum). Two media were used: a chemically defined medium (g/l): $\mathrm{MgSO}_{4} \cdot 7 \mathrm{H}_{2} \mathrm{O}$, $0.60 ; \mathrm{Na}_{2} \mathrm{MoO}_{4} \cdot 2 \mathrm{H}_{2} \mathrm{O}, 0.03 ; \mathrm{CaCl}_{2} \cdot 2 \mathrm{H}_{2} \mathrm{O}, 0.45 ; \mathrm{KH}_{2} \mathrm{PO}_{4}, 2.40$; $\mathrm{FeSO}_{4} \cdot 7 \mathrm{H}_{2} \mathrm{O}, 0.12$; and glucose 10 to 40 , and complex medium (g/l): $\mathrm{MgSO}_{4} \cdot 7 \mathrm{H}_{2} \mathrm{O}, 0.10 ; \mathrm{Na}_{2} \mathrm{MnO}_{4} \cdot 2 \mathrm{H}_{2} \mathrm{O}, 0.005 ; \mathrm{CaCl}_{2} \cdot 2 \mathrm{H}_{2} \mathrm{O}, 0.10$; $\mathrm{KH}_{2} \mathrm{PO}_{4}, 0.10 ; \mathrm{K}_{2} \mathrm{HPO}_{4}, 0.90 ; \mathrm{FeSO}_{4} \cdot 7 \mathrm{H}_{2} \mathrm{O}, 0.01$; molasses 20 to 80 $(47.6 \% \mathrm{w} / \mathrm{w}$ sucrose). In both media, the $\mathrm{pH}$ was adjusted to 7.0 . Flasks were incubated at $30^{\circ} \mathrm{C}$ for $120 \mathrm{~h}$ on a rotary shaker $(180$ rpm). The media were sterilized at $121^{\circ} \mathrm{C}$ for $20 \mathrm{~min}$. The solutions of salts and glucose (molasses) were sterilized separately and then, mixed prior to inoculation. Samples were taken every $24 \mathrm{~h}$.

\section{Cultivation of $\boldsymbol{A}$. chroococcum in stirred tank bioreactor}

The bioreactor was inoculated with bacterial biomass previously grown on a rotary shaker $(180 \mathrm{rpm})$ at $30^{\circ} \mathrm{C}$ for $48 \mathrm{~h}$. For batch cultivations, either chemically defined medium with $20 \mathrm{~g} / \mathrm{l}$ glucose or complex medium with $40 \mathrm{~g} / \mathrm{l}$ molasses were used. The working volume in the stirred tank bioreactor was $5 \mathrm{~L}$. After sterilization at $121^{\circ} \mathrm{C} / 20 \mathrm{~min}$, the bioreactor was inoculated with the suspension of bacterial biomass (optical density at $600 \mathrm{~nm}$ approximately 2.0 ) in the amount of the $10 \%$ of final working volume. During batch cultivation, the temperature was kept at $30^{\circ} \mathrm{C}$ and $\mathrm{pH}$ in the range of 7.3 to 7.8 by addition of $0.1 \mathrm{M} \mathrm{NaOH}$ or $0.1 \mathrm{M} \mathrm{H}_{2} \mathrm{SO}_{4}$. The partial pressure of oxygen $\left(\mathrm{pO}_{2}\right)$ was maintained at approximately $30 \%$ of air saturation by controlling the stirrer speed and the airflow rate. The batch phase of the fed-batch cultivation was done in the same manner. The feeding in the fed-batch process started when the carbon source concentration dropped below $2 \mathrm{~g} / \mathrm{l}$. This feeding involved the addition of a 3-fold concentrated medium (compared with the medium used for batch cultivation); was done in a few portions. Fed-batch cultivation was conducted until a constant biomass concentration was reached. The repeated batch cultivation started in the same way as batch cultivation. After the carbon source concentration dropped below $2 \mathrm{~g} / \mathrm{l}$, a portion of $3 \mathrm{~L}$ of culture was replaced with the same volume of fresh medium. The medium replacement was carried out for at least five times.

\section{Analytical procedures and bioprocess efficiency parameters}

The samples were centrifuged for $15 \mathrm{~min}$ at $4500 \mathrm{rpm}$ on a Harrier $18 / 80$, Sanyo centrifuge. Supernatants were used for glucose (or sucrose) determination and pellets were dried at $105^{\circ} \mathrm{C}$ to constant weight for dry weight measurements. Glucose or sucrose concentrations in the broth were determined as reducing sugars (Somogyi, 1951). Cell growth was also monitored by measuring the culture optical density at $600 \mathrm{~nm}$ (original samples were diluted at $10^{-1}$ ). The CFU number was detected by standard microbiological methods. In this research, all cultivation experiments were repeated and all sample determinations were done in triplicates. Statistical analysis of the obtained results (standard deviation calculation) was performed by "Wolfram Mathematica" software. Standard deviation was presented as inconsistency in figures and tables.

Bioprocess efficiency parameters [yield coefficient $\left(\mathrm{Y}_{\mathrm{x} / \mathrm{S}}\right)$ and productivity $(\mathrm{Pr})]$ were calculated by well known procedures. Biomass yield coefficient $\left(\mathrm{Y}_{\mathrm{X} / \mathrm{S}}\right.$ ) was calculated by the following equation:

$$
\mathrm{Y}_{\mathrm{X} / \mathrm{S}}=\frac{\mathrm{X}-\mathrm{X}_{0}}{\mathrm{~S}_{0}-\mathrm{S}}=\frac{\Delta \mathrm{X}}{\Delta \mathrm{S}}
$$


Table 1. Obtained biomass dry weight $(X)$, substrate $(S)$, consumed substrate concentration $(\Delta S)$ and biomass yield coefficient $\left(\mathrm{Y}_{\mathrm{X} / \mathrm{S}}\right)$ during cultivation on chemically defined media (MM) and complex media (CM) (rotary shaker).

\begin{tabular}{lccccc}
\hline Medium type & $\mathbf{S}_{\mathbf{0}}(\mathbf{g} / \mathbf{l})$ & $\mathbf{X}(\mathbf{g} / \mathbf{l})$ & $\mathbf{S}(\mathbf{g} / \mathbf{l})$ & $\Delta \mathbf{S}(\mathbf{g} / \mathbf{l})$ & $\mathbf{Y}_{\mathbf{x} / \mathbf{S}}(\mathbf{g} / \mathbf{g})$ \\
\hline & $10 \pm 0.14$ & $1.6 \pm 0.12$ & $0.5 \pm 0.12$ & $9.5 \pm 0.26$ & $0.166 \pm 0.02$ \\
$\mathrm{MM}$ & $20 \pm 0.26$ & $1.8 \pm 0.18$ & $2.5 \pm 0.16$ & $17.5 \pm 0.42$ & $0.103 \pm 0.01$ \\
& $30 \pm 0.32$ & $2.3 \pm 0.24$ & $12.8 \pm 0.32$ & $17.2 \pm 0.64$ & $0.133 \pm 0.02$ \\
& $40 \pm 0.42$ & $1.4 \pm 0.16$ & $28.3 \pm 0.46$ & $11.7 \pm 0.88$ & $0.120 \pm 0.02$ \\
& & & & & \\
$\mathrm{CM}$ & $9.5 \pm 0.15$ & $1.7 \pm 0.14$ & $0.2 \pm 0.1$ & $9.3 \pm 0.25$ & $0.179 \pm 0.02$ \\
& $19.0 \pm 0.26$ & $2.1 \pm 0.18$ & $4.0 \pm 0.32$ & $15.0 \pm 0.58$ & $0.138 \pm 0.02$ \\
& $28.6 \pm 0.28$ & $2.3 \pm 0.22$ & $10.0 \pm 0.48$ & $18.6 \pm 0.66$ & $0.126 \pm 0.02$ \\
& $38.1 \pm 0.41$ & $2.9 \pm 0.26$ & $22.0 \pm 0.40$ & $16.1 \pm 0.81$ & $0.180 \pm 0.02$ \\
\hline
\end{tabular}

Where, $\mathrm{X}$ and $\mathrm{X}_{0}$ are biomass concentration at the end and the beginning of cultivation and $S_{0}$ and $S$ are substrate concentration at the beginning and the end of cultivation, respectively.

Bioprocess productivity $(\mathrm{Pr})$ was determined by the equation:

$\operatorname{Pr}=\frac{\mathrm{X}-\mathrm{X}_{0}}{\mathrm{t}}$

Where, $\mathrm{t}$ is the cultivation time.

\section{RESULTS AND DISCUSSION}

\section{Optimization of medium composition for cultivation of A. chroococcum}

The main goal of this investigation was to define a medium composition and a cultivation technique suitable for producing $A$. chroococcum biomass at large scale. Chemically defined and complex media were used for the cultivation of $A$. chroococcum to define the benefits of the media. The chemically defined media contained glucose as a carbon source and inorganic salts as a source of microelements $\left(\mathrm{Mo}^{2+}, \mathrm{Mn}^{2+}, \mathrm{Fe}^{2+}\right.$ and $\left.\mathrm{Ca}^{2+}\right)$ that are important for the growth of $A$. chroococcum (Page, 1986; Fallik et al., 1993; Yates et al., 1997). The complex media was composed of sugar beet molasses $(47.6 \% \mathrm{w} / \mathrm{w}$ sucrose) as a carbon source and inorganic salts. In preliminary research, $A$. chroococcum was cultivated on chemically defined media with different glucose concentrations (10 to $40 \mathrm{~g} / \mathrm{l})$ as well as on complex media with different sucrose concentration (9.5 to $38.1 \mathrm{~g} / \mathrm{l})$, respectively. Maximal values of dry biomass concentrations during $A$. chroococcum cultivation on chemically defined media are presented in Table 1. The highest biomass concentration was obtained with $30 \mathrm{~g} / \mathrm{l}$ of glucose, but there was $12.8 \mathrm{~g} / \mathrm{l}$ unconsumed carbon source in the medium at the end of cultivation. However, it is important to point out that high glucose concentrations in the medium stimulate PHB synthesis, which has the effect of additionally increasing the biomass concentration (Kim, 2000; Quagliano et al., 2001). Note that, the cultivation with $20 \mathrm{~g} / \mathrm{l}$ of glucose resulted in a slightly lower biomass concentration but the glucose was almost completely consumed. Glucose concentration of $40 \mathrm{~g} / \mathrm{l}$ did not result in higher biomass concentration and substrate consumption efficiency. During cultivation of $A$. chroococcum on chemically defined media, the CFU number was also determined (data not shown) and it was in the range of $5 \times 10^{7}$ to $2 \times 10^{8} \mathrm{ml}^{-1}$. Cultivation of $A$. chroococcum on chemically defined media was characterized by relatively low biomass yield coefficients $\left(Y_{x / S} ; 0.103\right.$ to $\left.0.166 \mathrm{~g} / \mathrm{g}\right)$, which is probably a consequence of relatively high energy demand for bacterial metabolism, as already reported in literature (Yates et al., 1997; Savenkova et al., 1999; Kisten et al., 2006).

On the basis of the stated results, the chemically defined medium with $20 \mathrm{~g} / \mathrm{l}$ of glucose was selected for further experiments in which the effect of the concentration of inorganic salts on growth was examined. A. chroococcum was cultivated on this medium with inorganic salts contents that represented 65 and $130 \%$ of those in the medium used in the previous experiments. The inorganic salts content did not have significant effect on the biomass concentration and substrate consumption efficiency (data not shown). Therefore, for further investigation standard inorganic salts concentration was used.

A. chroococcum was also cultivated on complex media with different molasses concentrations $(20$ to $80 \mathrm{~g} / \mathrm{l}$ and 9.5 to $38.1 \mathrm{~g} / \mathrm{l}$ of sucrose) in order to define a composition that can be used for cultivation at large scale (Table 1). The increase of sucrose concentration until $28.6 \mathrm{~g} / \mathrm{l}$ (60 $\mathrm{g} / \mathrm{l}$ molasses) resulted in a slight increase in biomass concentration and substrate consumption $(\Delta \mathrm{S})$. A further increase of sucrose concentration to $38.1 \mathrm{~g} / \mathrm{l}(80 \mathrm{~g} / \mathrm{l}$ molasses) increased the biomass concentration further but not the substrate consumption $(\Delta S)$. As in the experiments with the high glucose concentrations in chemically defined medium, the high sucrose concentrations probably led to the accumulation of large amounts of 


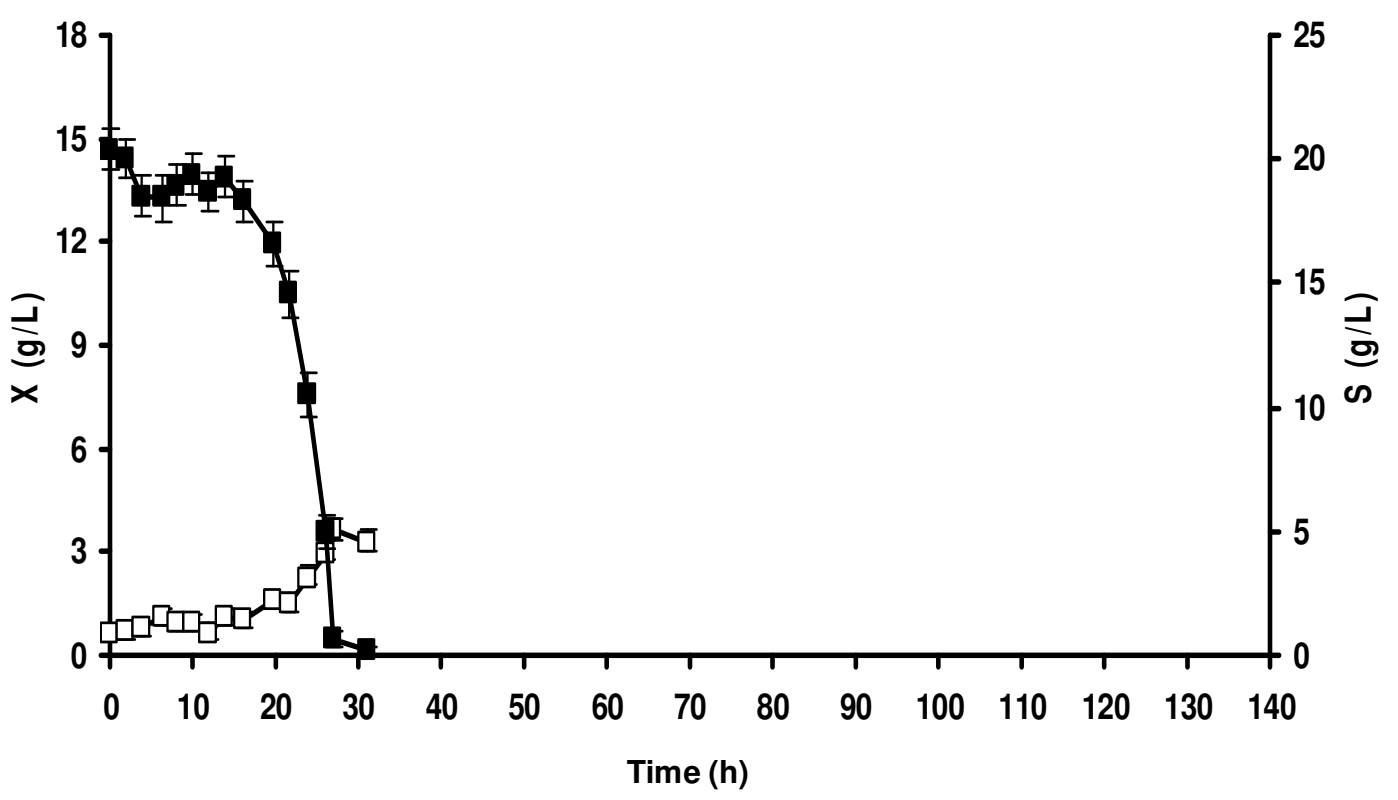

Figure 1. Changes of biomass dry weight $(X ; \square)$ and glucose concentration $(S ; \varpi)$ during batch cultivation of $A$. chroococcum on chemically defined medium.

PHB which resulted in higher biomass concentration (Kim, 2000; Quagliano et al., 2001). The biomass concentrations obtained on complex media were slightly higher than those obtained on defined media and were probably a consequence of the presence of nitrogen in these media that probably enhanced bacterial growth. For the same reason, slightly higher biomass yield coefficients $\left(\mathrm{Y}_{\mathrm{X} / \mathrm{S}}\right)$ were also observed $(0.126$ to $0.180 \mathrm{~g} / \mathrm{g}$; Table 1). For further research, complex medium that contains $19.0 \mathrm{~g} / \mathrm{l}$ of sucrose ( $40 \mathrm{~g} / \mathrm{l}$ of molasses) was selected because of the fact that, almost all sucrose was used for bacterial growth $(\Delta S=15 \mathrm{~g} / \mathrm{l})$.

\section{Cultivation of $A$. chroococcum in stirred tank bioreactor}

After the rotary shaker experiments described earlier, selected media were used for the cultivation of $A$. chroococcum in a stirred tank bioreactor. Batch, fed batch and repeated batch techniques were used in an attempt to maximize biomass production. In batch cultivation of $A$. chroococcum on chemically defined medium, the substrate (glucose $20 \mathrm{~g} / \mathrm{l}$ ) was completely consumed after only $32 \mathrm{~h}$ (Figure 1). Changes of biomass concentration were closely related to the changes of culture optical density thus, indicating that the culture optical density could be used as good indicator of bacterial growth (data not shown). During this cultivation, the $\mathrm{pH}$ remained within the range of 7.0 to 7.5.

Batch cultivation of $A$. chroococcum was also done on complex medium with $19.0 \mathrm{~g} / \mathrm{l}$ of sucrose $(40 \mathrm{~g} / \mathrm{l}$ of molasses), as presented in Figure 2. Here again, changes of culture optical density were closely related to the changes of biomass concentration (data not shown). In this cultivation, the $\mathrm{pH}$ increased slightly from 7.0 to a final value (within the range of 7.5 to 8.0 ) as a consequence of medium components (salts) consumption. The maximal value of biomass concentration was higher than that obtained in the cultivation on chemically defined medium and much higher than the values obtained in flask culture on the rotary shaker. The obtained data are in agreement with those in literatures (Quagliano et al., 2001; Kisten et al., 2006).

In this investigation, fed batch cultivation technique was also studied in order to increase biomass yield and bioprocess productivity. In fed batch cultivation on both media, a few portions of triple concentrated medium were added. In order to add approximately the same amount of carbon source to the bioreactor, higher volume of the feed portion was used during cultivation on chemically defined $(700 \mathrm{ml})$ than on the complex medium $(500 \mathrm{ml})$. Furthermore, the complex medium contained a nitrogen source (that was not present in chemically defined medium) and this additionally stimulated bacterial growth. In both cases (Figures 3 and 4), the maximal biomass concentrations obtained were significantly higher that those obtained in the corresponding batch cultivations. During fed batch cultivation of $A$. chroococcum on the chemically defined medium, the achieved maximal biomass concentration was $5.4 \mathrm{~g} / \mathrm{l}$ and the CFU number was $6.4 \times 10^{8} \mathrm{ml}^{-1}$. A significantly higher biomass concentration $\left(15.6 \mathrm{~g} / \mathrm{l}\right.$ and CFU number of $\left.7.6 \times 10^{8} \mathrm{ml}^{-1}\right)$ was obtained during cultivation on the complex medium as a consequence of the nitrogen source presence in the feed that stimulated the bacterial growth. 


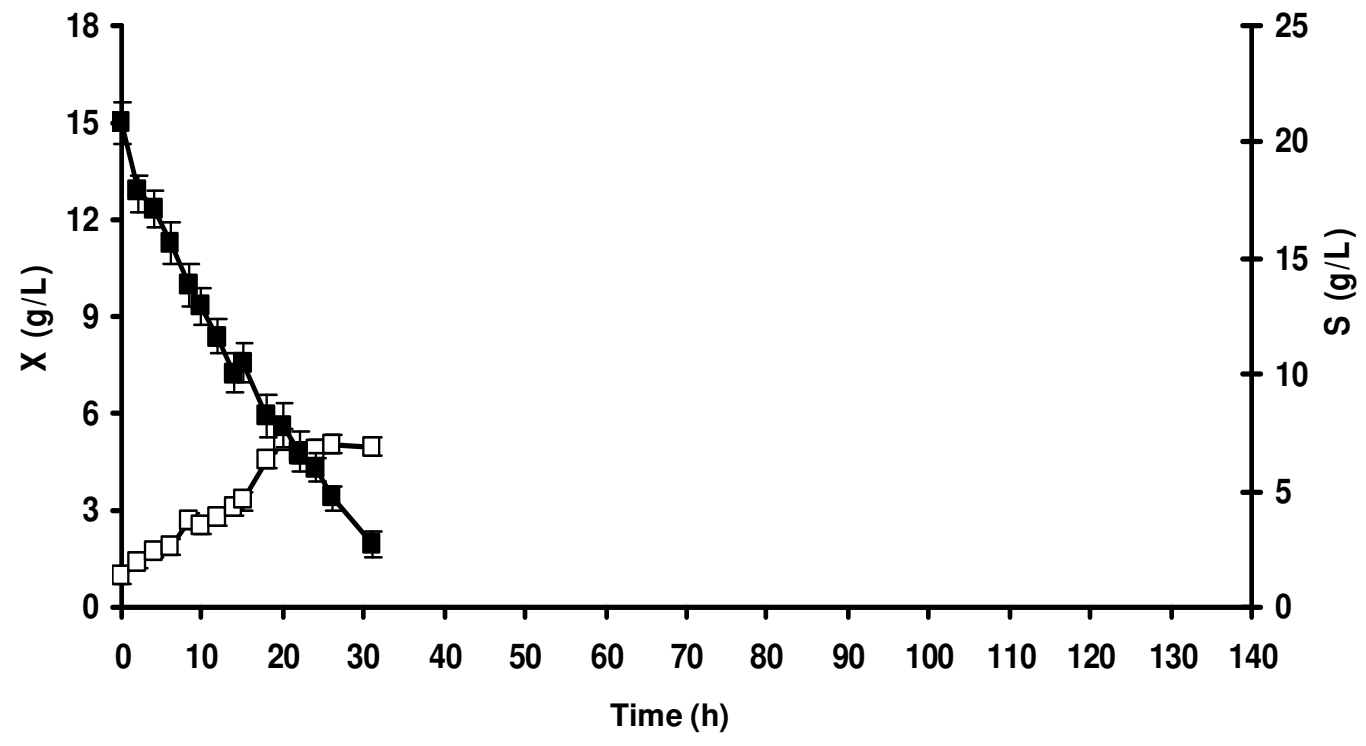

Figure 2. Changes of biomass dry weight $(X ; \square)$ and sucrose concentration ( $S$; $\mathbf{m})$ during batch cultivation of $A$. chroococcum on complex medium.

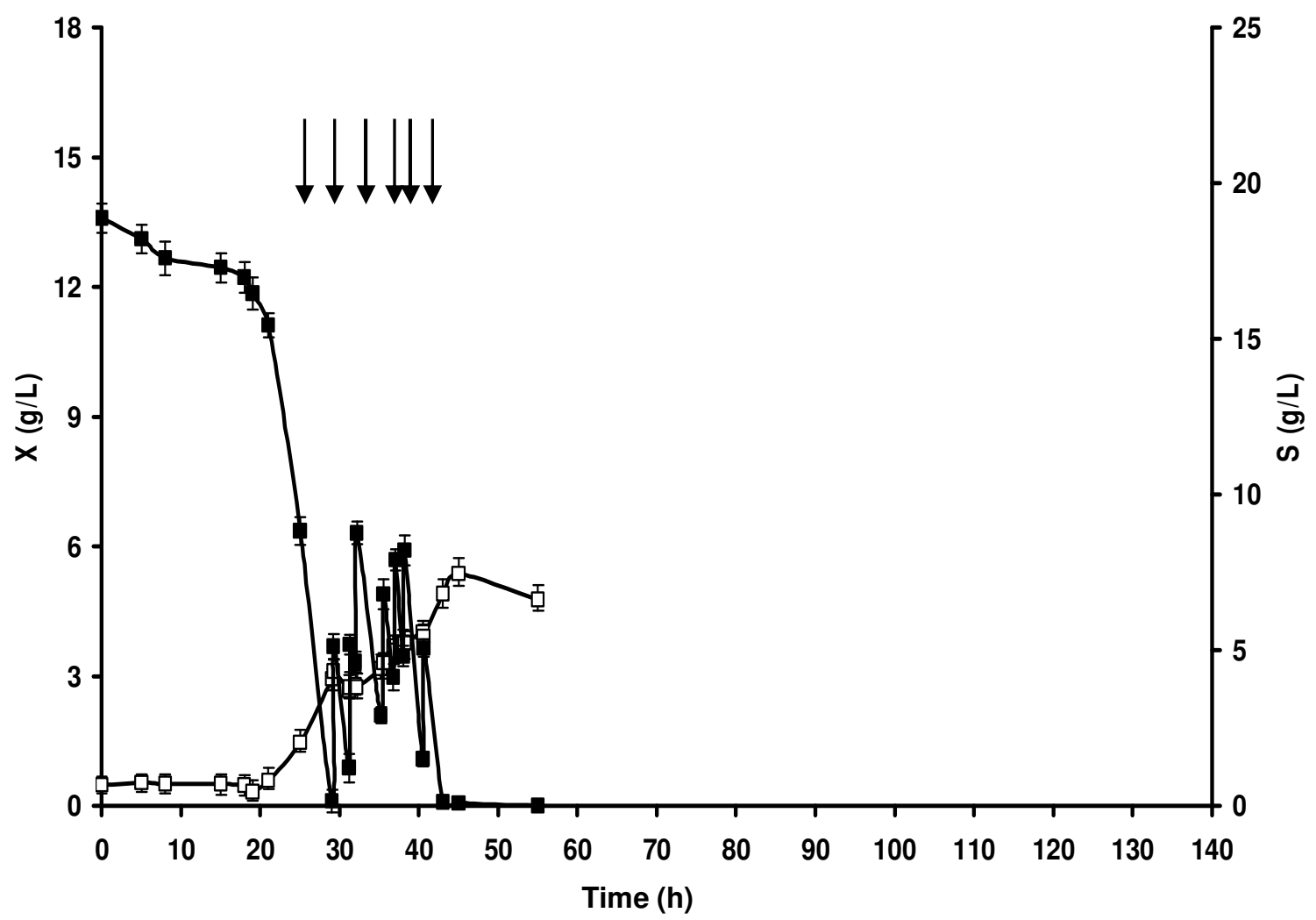

Figure 3. Changes of biomass dry weight $(X ; \square)$ and glucose concentration $(S ; \boldsymbol{m})$ during fed batch cultivation of A. chroococum on chemically defined medium. Arrows represent the moment of fresh medium addition.

Repeated batch cultivation was also explored in order to improve bioprocess productivity. During the cultivation on both media, five exchanges of bioreactor volume were done and each medium exchange was performed when the carbon source was almost completely consumed. Higher biomass concentrations were obtained during cultivation on complex medium as a consequence of nitrogen presence in this medium (Figures 5 and 6). In 


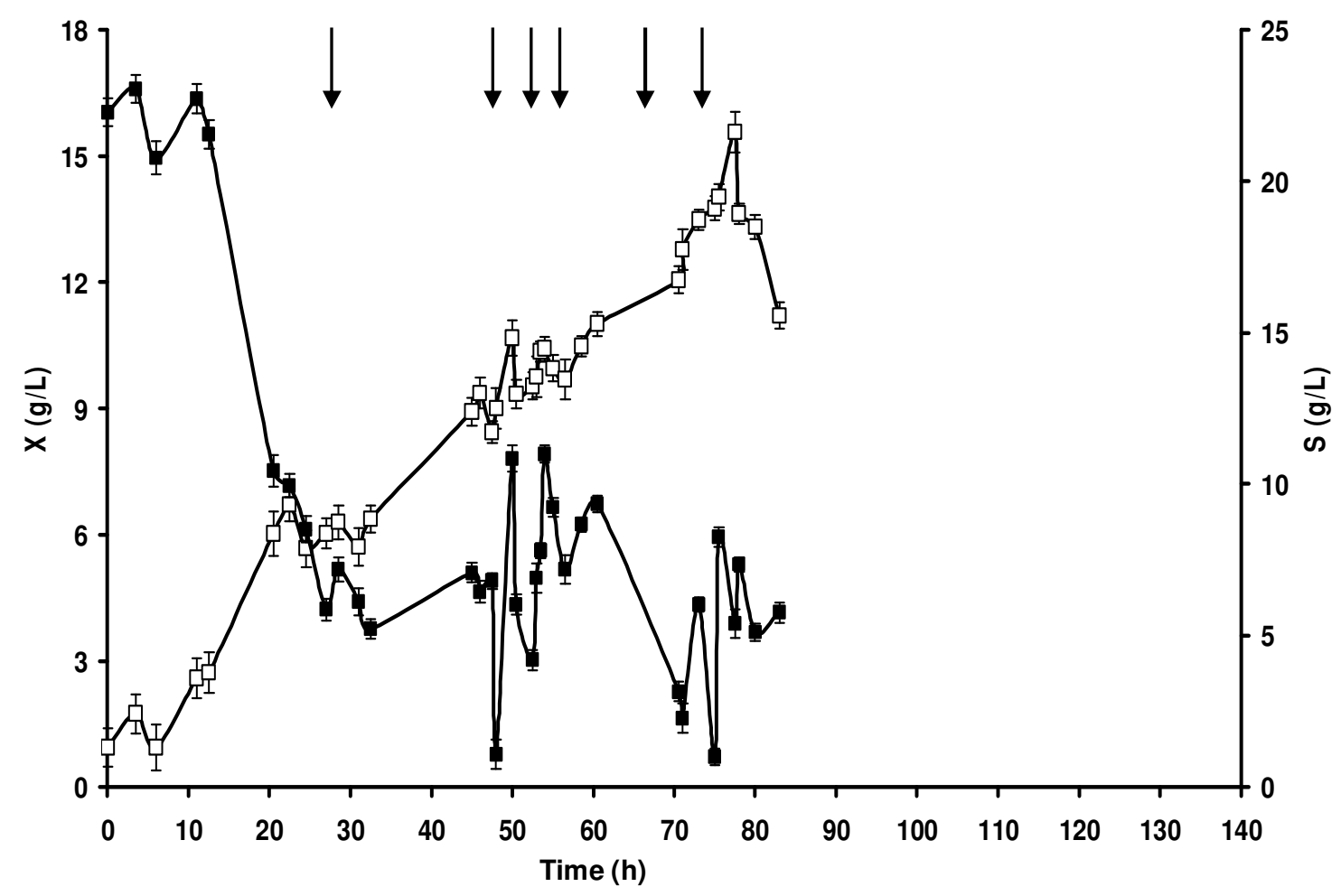

Figure 4. Changes of biomass dry weight $(X ; \square)$ and sucrose concentration $(S ; \mathbf{m})$ during fed batch cultivation of A. chroococcum on complex medium. Arrows represent the moment of fresh medium addition.

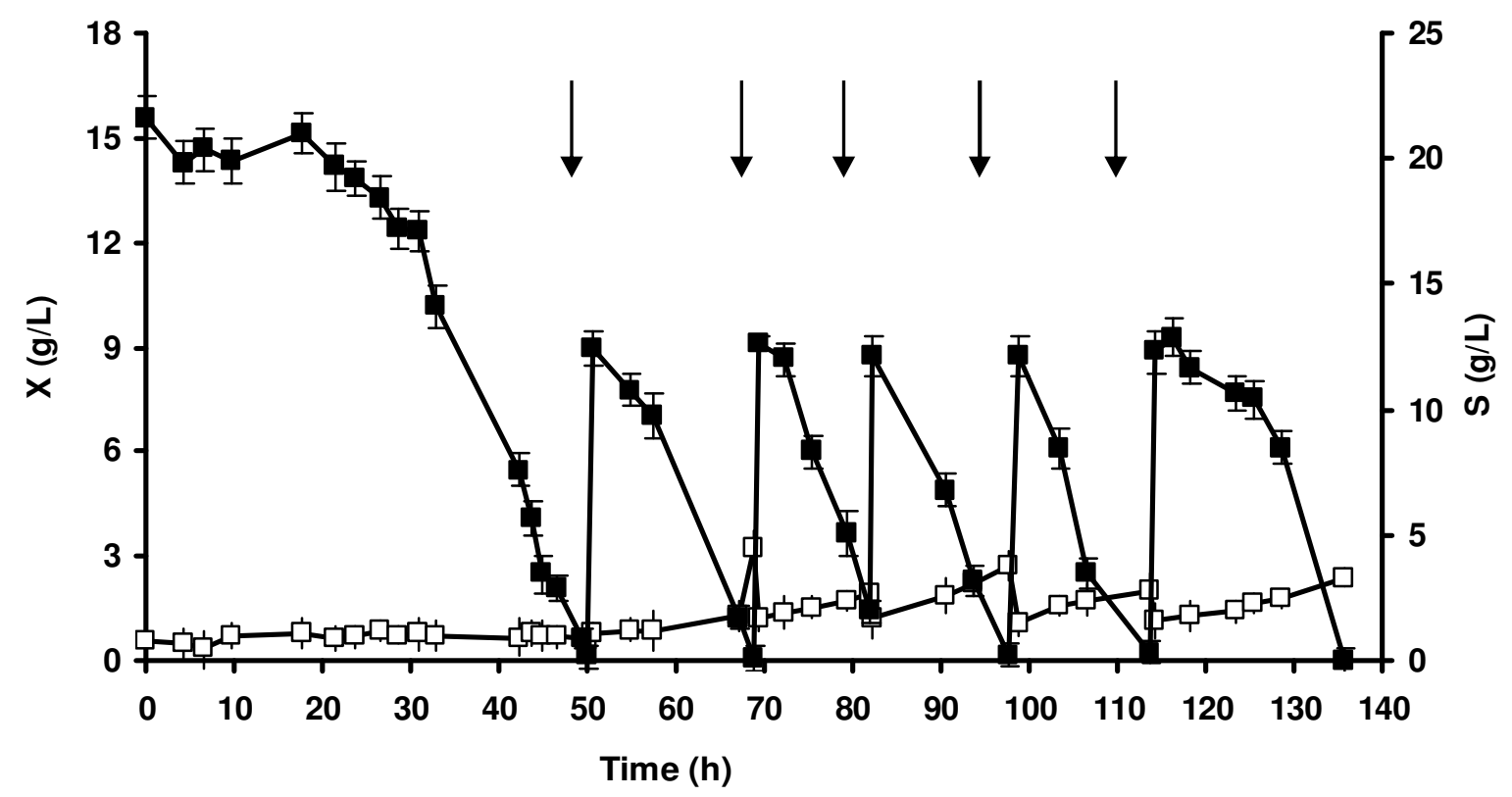

Figure 5. Changes of biomass dry weight $(X ; \square)$ and glucose concentration $(S ; \boldsymbol{\Xi})$ during repetead batch cultivation of A. chroococcum on chemically defined medium. Arrows represent the moment of volume exchange.

repeated batch, cultivation on chemically defined medium biomass concentrations at the moment of medium exchange were within the range of 2.4 to $2.7 \mathrm{~g} / \mathrm{l}$ and on complex medium was within the range of 7.6 to $8.1 \mathrm{~g} / \mathrm{l}$, respectively. On the basis of the obtained results, it is clear that repeated batch cultivation is the most appropriate cultivation technique for stable and long time period cultivation of $A$. chroococcum. 


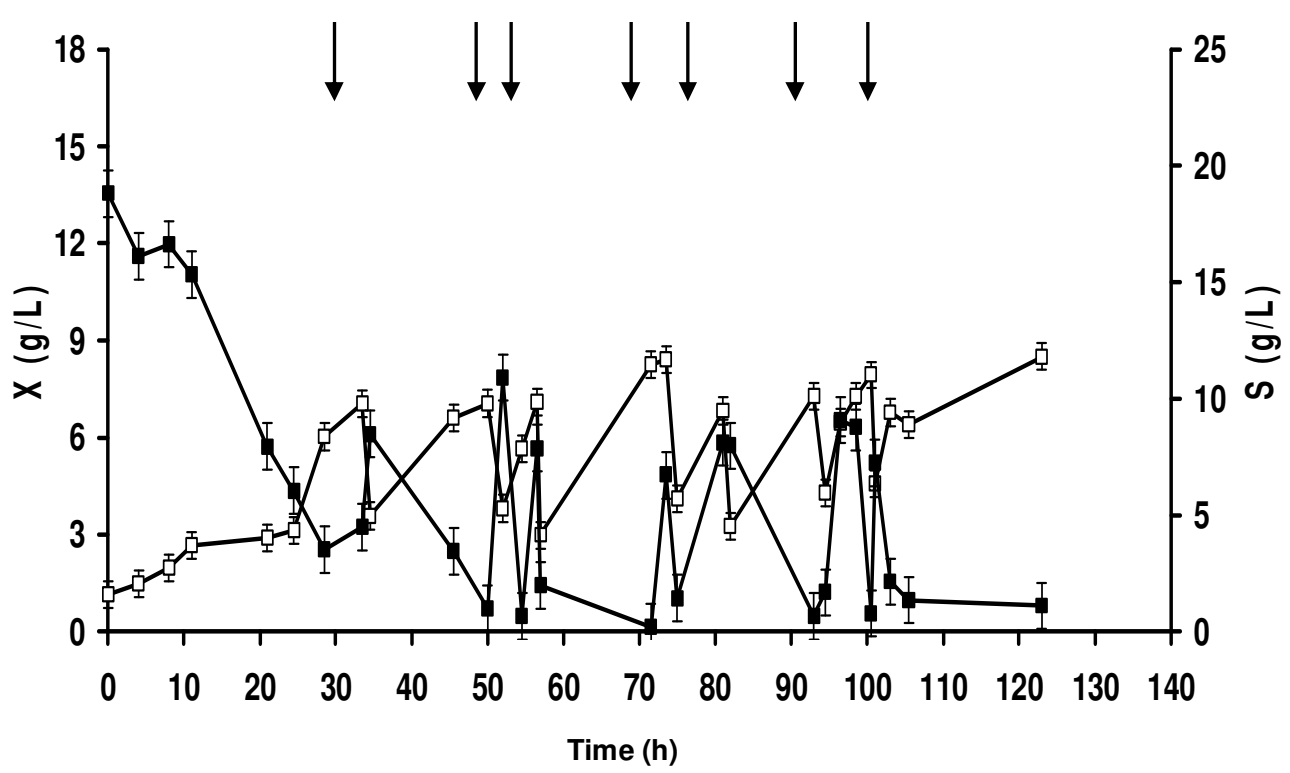

Figure 6. Changes of biomass dry weight $(X ; \square)$ and sucrose concentration $(S ; \mathbf{a})$ during repeated batch cultivation of $A$. chroococcum on complex medium. Arrows represent the moment of volume exchange.

Table 2. Bioprocess efficiency parameters of $A$. chroococcum cultivation on chemically defined medium (MM) and complex medium (CM) in stirred tank bioreactor.

\begin{tabular}{lcccccc}
\hline \multirow{2}{*}{$\begin{array}{c}\text { Medium type/ } \\
\text { Parameter }\end{array}$} & \multicolumn{2}{c}{ Batch cultivation } & \multicolumn{2}{c}{ Fed batch cultivation } & \multicolumn{2}{c}{ Repeated batch cultivation } \\
\cline { 2 - 6 } & $\mathbf{M M}$ & $\mathbf{C M}$ & $\mathbf{M M}$ & $\mathbf{C M}$ & $\mathbf{M M}$ & $\mathbf{C M}$ \\
\hline $\mathrm{CFU}_{\mathrm{M}} \times 10^{7}\left(\mathrm{ml}^{-1}\right)$ & $15.0 \pm 0.5$ & $38.0 \pm 0.8$ & $64.0 \pm 1.0$ & $76.0 \pm 1.5$ & $21.8 \pm 0.6$ & $33.0 \pm 0.7$ \\
$\mathrm{X}_{\mathrm{M}}(\mathrm{g} / \mathrm{l})$ & $3.6 \pm 0.36$ & $5.1 \pm 0.34$ & $5.4 \pm 0.32$ & $15.6 \pm 0.48$ & $3.2 \pm 0.38$ & $8.4 \pm 0.42$ \\
$\mathrm{Y} / \mathrm{s}(\mathrm{g} / \mathrm{g})$ & $0.147 \pm 0.02$ & $0.228 \pm 0.03$ & $0.157 \pm 0.02$ & $0.418 \pm 0.04$ & $0.223 \pm 0.03$ & $0.476 \pm 0.04$ \\
$\operatorname{Pr}(\mathrm{g} /(\mathrm{Lh}))$ & $0.095 \pm 0.01$ & $0.134 \pm 0.01$ & $0.119 \pm 0.01$ & $0.201 \pm 0.02$ & $0.141 \pm 0.02$ & $0.302 \pm 0.02$ \\
\hline
\end{tabular}

\section{Comparison between different cultivation techniques and media}

The results obtained during the cultivation of $A$. chroococcum with different cultivation techniques on chemically defined medium are presented in Table 2 . The highest biomass concentration $\left(\mathrm{X}_{\mathrm{M}}\right)$ and the cell number $\left(\mathrm{CFU}_{\mathrm{M}}\right)$ were detected during fed batch cultivation, but only after a relatively long cultivation period and therefore, the biomass productivity was relatively low. At the same time, during fed batch cultivation on chemically defined medium, a relatively high proportion of the glucose remained unconsumed, which indicates that further optimization of this cultivation technique is necessary. The highest bioprocess productivity was detected during the repeated batch cultivation of $A$. chroococcum and consequently, this cultivation technique has the highest potential for application in large scale production. During the cultivation of $A$. chroococcum on complex medium (Table 2), higher bioprocess efficiency was observed compared with the cultivation on chemically defined medium. The highest biomass concentration and CFU number were detected during fed batch cultivation, but after relatively long cultivation period. During repeated batch cultivation, higher bioprocess productivity was observed compared with the fed batch cultivation. On the basis of these results, repeated batch technique can be recommended for use for large scale cultivation of $A$. choococcum because it had the highest bioprocess productivity and stability through a relatively long period of time. Therefore, for industrial production of different microbial starter cultures (for example, yeast, acetic and lactic acid bacteria or bacteria for wastewater treatment) or products (ethanol or organic acids) this cultivation technique could be considered as an alternative for the currently utilized cultivation techniques (mostly batch or fed batch) due to better bioprocess performance.

Comparison between the media showed that, complex medium was more favourable for biomass growth. Furthermore, from economic point of view for industrial production, the use of complex carbon soucres (molasses, starch or cellulose hydrolysates) instead of pure 
sugars considerably reduces the price of fermentation medium and consequently, the price of the final bioprocess product. For example, comparison between current prices of pure sucrose (cca 510 US dollars/tonne) and molasses (cca 154 US dollars/tonne) pointed out that, molasses is approximately 3.3 times cheaper than pure sucrose (www.ers.usda.gov and www.agra-net.com).

\section{Conclusions}

In this work $A$. chroococcum was cultivated using different media and cultivation techniques in order to optimize the biomass production. Chemically defined and complex media with $20 \mathrm{~g} / \mathrm{l}$ of sugar were the most appropriate media for batch cultivation in stirred tank bioreactor. In order to obtain higher bioprocess efficiency, fed batch and repeated batch techniques were studied. During these cultivations, significant increase of biomass concentrations were obtained compared with the batch cultivation. Comparison between the different cultivation techniques on the basis of bioprocess efficiency parameters showed that, repeated batch cultivation would be the optimal technique for the production of bacterial biomass at industrial scale.

\section{ACKNOWLEDGEMENTS}

The authors are grateful for the financial support provided by the Ministry of Science, Education and Sport Republic of Croatia (Grants No. 058-0581990-2004 and 0580581990-1997).

\section{REFERENCES}

Bakulin MK, Grudtsyna AS, Pletneva AY (2007). Biological fixation of nitrogen and growth of bacteria of the genus Azotobacter in liquid media in the presence of perflourocarbons. Appl. Biochem. Microbiol. 43: 399-402.

Behl RK, Sharma H, Kumar V, Narula N (2003). Interactions amongst mycorhiza, Azotobacter chroococcum and root characteristics of wheat varieties. J. Agron. Crop Sci. 189: 151-155.

Fallik E, Hartel P, Robson RL (1993). Presence of vanadium nitrogenase in Azotobacter paspali. Appl. Environ. Microbiol. 59: 1883-1886.

Funa N, Ozawa H, Hirata A, Horinouchi S (2006). Phenolic lipid synthesis by type III polyketide synthases is essential for cyst formation in Azotobacter vinelandii. PNAS, 103: 6356-6361.

Gimmestad M, Steigedal M, Ertesvåg H, Moreno S, Christensen BE, Espín G, Valla S (2006). Identification and characterization of an Azotobacter vinelandii type I secretion system responsible for export of the AlgE-Type mannuronan C-5-epimerases. J. Bacteriol. 188: 5551-5560.

Hine PW, Lees H (1976). The growth of nitrogen-fixing Azotobacter chroococcum in continuous culture under intense aeration. Can. J. Microbiol. 22: 611-618.

Juarez B, Martinez-Toledo MV, Gonzalez- Lopez J (2005). Growth of Azotobacter chroococcum in chemically defined media containing $\mathrm{p}$ hidroxybenzoic acid and protocatechuic acid. Chemosphere, 59: 1361-1365.
Kim BS (2000). Production of poly (3-hydroxybutyrate) from inexpensive substrates. Enzyme Microb. Technol. 27: 774-777.

Kisten AG, Kurdish IK, Bega ZT, Tsarenko AY (2006). The effect of several factors on the growth of pure and mixed cultures of Azotobacter chroococcum and Bacillus subtilis. Appl. Biochem. Microbiol. 42: 278-283.

Kumar V, Behl RK, Narula N (2001). Establishment of phosphate solubilizing strains of Azotobacter chroococcum in the rhizosphere and their effect on wheat cultivars under greenhouse conditions. Microbiol. Res. 156: 87-93.

Kumar GP, Yadav SK, Thawale PR, Singh SK, Juwarkar AA (2008). Growth of Jatropha curcas on heavy metal contaminated soil amended with industrial wastes and Azotobacter-A greenhouse study. Bioresour. Technol. 99: 2078-2082.

Lees H, Postgate JR (1973). The behaviour of Azotobacter chroococcum in oxygen- and phosphate-limited chemostat cultures. J. Gen. Microbiol. 75: 161-166.

Martinez-Toledo MV, Gonzalez-Lopez J, Rodales B, Pozo C, Salmeron V (1995). Production of poly-b-hydroxybutyrate by Azotobacter chroococcum $\mathrm{H} 23$ in chemically defined medium and alpechin medium. J. Appl. Bacteriol. 78: 413-418.

Moser A (1988). Bioprocess Technology Kinetics and Reactors. Springer Verlag, New York-Wien, Austria.

Page WJ (1986). Sodium dependent growth of Azotobacter chroococcum. Appl. Environ. Microbiol. 51: 510-514.

Pal S, Manna A, Paul AK (1997). Induction of encystment and poly- $\beta$ hydroxybutyric acid production by Azotobacter chroococcum MAL201. Curr. Microbiol. 35: 327-330.

Pena C, Miranda L, Segura D, Núñez C, Espín G, Galindo E (2002). Alginate production by Azotobacter vinelandii mutants altered in polybeta-hydroxybutyrate and alginate biosynthesis. J. Ind. Microbiol. Biotechnol. 29: 209-213.

Pozo C, Martinez-Toledo MV, Rodales B, Gonzalez-Lopez J (2002). Effects of culture conditions on the production of polyhydroxyalkanoates by Azotobacter chroococcum H23 in media containing a high concentration of alpechin (wastewaters from olive oil mills) as a primary carbon source. J. Biotechnol. 97:125-131.

Revillas JJ, Rodelas B, Pozo C, Martínez-Toledo MV, González-López $J$ (2000). Production of B-group vitamins by two Azotobacter strains with phenolic compounds as sole carbon source under diazotrophic and adiazotrophic conditions. J. Appl. Microbiol. 89: 486-493.

Quagliano J, Amarilla F, Fernandes E, Mata D, Miyazaki S (2001). Effect of simple and complex carbon sources, low temperature culture and complex carbon feeding policies on poly- $\beta$-hydroxybutyric acid (PHB) content and molecular weight (Mw) from Azotobacter chroococcum 6B. W. J. Microbiol. Biotechnol. 17: 9-14.

Sabra WA, Zeng AP, Lünsdorf H, Deckwer WD (2000). Effect of oxygen on formation and structure of Azotobacter vinelandii: alginate and its role in protecting nitrogenase. Appl. Environ. Microbiol. 66: 40374044.

Sabra WA, Zeng AP, Deckwer WD (2001). Bacterial alginate: physiology, product quality and process aspects. Appl. Microbiol. Biotechnol. 56: 315-325.

Savenkova L, Gercberga Z, Kizhlo Z, Stegantseva E (1999). Effect of phosphate supply and aeration on poly-b-hydroxybutyrate production in Azotobacter chroococcum. Proc. Biochem. 34:109-114.

Segura D, Guzmán J, Espín G (2003a). Azotobacter vinelandii mutants that overproduce poly-beta-hydroxybutyrate or alginate. Appl. Microbiol. Biotechnol. 63: 159-163.

Segura D, Cruz T, Espín G (2003b). Encystment and alkylresorcinol production by Azotobacter vinelandii strains impaired in poly- $\beta$ hydroxybutyrate synthesis. Arch. Microbiol. 179: 437-443.

Somogyi M (1951). Notes on sugar determination. J. Biol. Chem. 195: pp. 19-23.

Vessey JK (2003). Plant growth promoting rhizobacteria as biofertilizers. Plant Soil, 255: 571-586.

Yates MG, Souza EM, Kahindi JH (1997). Oxygen, hydrogen and nitrogen fixation in Azotobacter. Soil Biol. Biochem. 29: 863-869. 